\title{
Gastric Cancer Surgery During the Pandemic: What It Costs?
}

\author{
Hilmi Yazici ${ }^{1}$ [ $\cdot$ Ayse Eren ${ }^{1} \cdot$ Tevfik Kivilcim Uprak $^{1} \cdot$ Cihan Sahan $^{1} \cdot$ Ahmet Cem Esmer $^{1} \cdot$ Sevket Cumhur Yegen $^{1}$
}

Accepted: 29 October 2021 / Published online: 22 November 2021

(c) Springer Science+Business Media, LLC, part of Springer Nature 2021

\begin{abstract}
Background From the early days of 2020, the COVID-19 pandemic continues to change whole life all around the world. Oncological patients are the most affected populations since these days. Because of decreasing numbers in surgery and endoscopy, gastric cancer patients had difficulties in treatment and diagnoses. Therefore, the early and long-term results may be affected during the pandemic. In this study, we aimed to evaluate pandemia effects on gastric cancer surgery in a single center. Patients-Methods Patients were categorized as the COVID group and the Pre-COVID group. Patients who received neoadjuvant chemotherapy were excluded from the study. In the COVID period, 50 patients underwent gastric cancer surgery, while 64 were operated on in the pre-COVID period. Patients' demographics and clinical and pathological outcomes were evaluated. Results There was no statistically significant difference in both periods among patient characteristics such as age, gender, and body mass index. Pre-operative laboratory results were similar between two groups. Although there was no difference in operation types, an increase was detected in Clavien-Dindo grade 3 and higher complications during the COVID period. During the pandemic, there was a significant difference in the pathological outcomes. Peritoneal cytology-positive patients were higher in the COVID group. More lymphovascular invasions were also detected in the COVID period. Finally, it resulted stage differences between two groups.

Conclusion Because of COVID-19's heavy burden on healthcare system, delays in the diagnosis and treatment of oncological patients may occur. Therefore, this may be affected pathological and survival outcomes of cancer patients. Finally, further investigations are needed.
\end{abstract}

Keywords Cancer $\cdot$ COVID $\cdot$ Gastric $\cdot$ Pathology

\section{Background}

Due to the heavy burden of the COVID-19 pandemic on the entire health systems, delays and difficulties could arise in the diagnosis, treatment, and follow-up processes of patients admitted to the hospital for other reasons. Among all patient groups, especially oncological patients were the most affected population by this condition [1]. Especially during the periods when the COVID-19 pandemic peaked and all branches of the health system struggled with it, the numbers of elective endoscopic procedures and surgical interventions were decreased [2]. Therefore, the diagnosis and the treatment of gastrointestinal system cancers were seriously affected. According to the latest data, the number of gastric cancer diagnoses was almost $50 \%$ before

\section{Hilmi Yazici}

1 General Surgery Department, Marmara University Pendik Research and Treatment Hospital, Istanbul, Turkey the COVID-19 pandemic in the UK [3]. As the number of endoscopies was decreased, there would be delays in recognizing cancers, and it would be expected that it may result in some stage uprises in this pandemic period. There are many studies that more extended waiting periods before surgery did not affect the pathological outcomes of the patients [4]. The aim of this study was to search the effects of COVID-19 pandemia on pathological and surgical outcomes of gastric cancer patients.

\section{Patients-Methods}

The first COVID-19 case in Turkey was detected on March 11, 2020. From this date, all branches of the health care system were adopted to the pandemic conditions. Therefore, we designed this retrospective study to examine the consequences of changing conditions on gastric cancer surgery. In this study, patients who underwent gastric cancer surgery 
between May 2019 and March 2020 before the pandemic period (pre-COVID) and April 2020-December 2020 after pandemia (COVID) at Marmara University Hospital's general surgery department were examined. Only patients diagnosed with gastric adenocarcinoma were included in the study. A total of 177 gastric adenocancer surgeries were performed over the entire 18-month period. While 96 gastric cancer surgeries were performed in the pre-COVID period, 81 patients underwent gastric cancer surgeries in the COVID period. The patients who underwent emergency surgeries due to bleeding, obstruction, and perforation were excluded. The number of patients receiving neoadjuvant chemotherapy (NCT) was 17 in the pre-COVID period, and it was 13 in the COVID period. The patients who received NCT were excluded from the study due to prolonged and different waiting times before surgery. Finally, 64 patients in the pre-COVID period, and 50 patients in the COVID period were found to be evaluable for elective gastric cancer surgery (Fig. 1).

In addition to demographic data of 114 patients, such as age, gender, and body mass index (BMI), time from endoscopic diagnosis to surgery was calculated. Perioperative values such as preoperative-postoperative hemoglobin $(\mathrm{Hb})$ concentrations, tumor markers such as carsinoembriogenic antigen (CEA), carbohydrate antigen (CA)
19-9, carbohydrate antigen (CA) 125, surgery types, combined-organ resections, and grade 3 and higher complications according to the Clavian-Dindo classification, were recorded. Pathological details such as T, N, M, stages according to AJCC Cancer Staging 8th edition, lymphovascular invasions, and adherent organ invasions such as the omentum, spleen, and pancreas were noted.

This study was approved by the Ethics Committee of the Marmara University (No: 09.2021.356).

SPSS version 24.0 (SPSS Inc. IBM, Chicago, US) was used for statistical analysis. Mean, median, standard deviation, and interquartile range (IQR) values were used for descriptive data. The student's $t$-test was used to analyze continuous quantitative variables, and the Mann-Whitney $U$ test was used for non-parametric data analysis. The $\chi^{2}$ test was used to compare qualitative data.

\section{Results}

There was no statistically significant difference in patients' demographics such as age, gender, and body mass index between the two periods (Table 1). Among the 33 patients who underwent emergency surgery, 15 were in the

Fig. 1 Patient flowchart

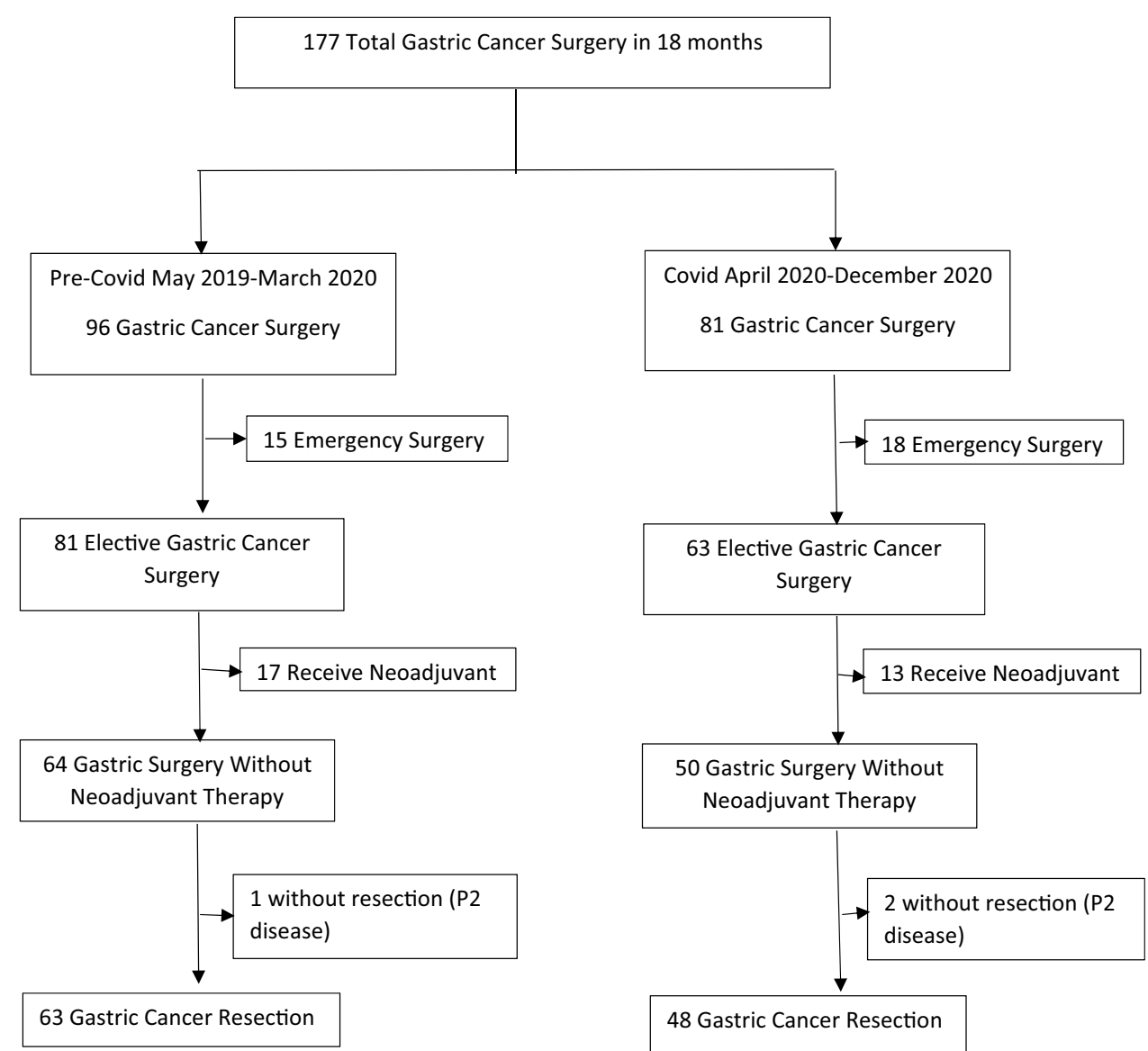


Table 1 Patient demographics in both periods

\begin{tabular}{|c|c|c|c|}
\hline Total N : 114 & $\begin{array}{l}\text { Pre-COVID (N: 64) } \\
\text { Median (IQR)-Mean } \\
( \pm \text { SD) }\end{array}$ & $\begin{array}{l}\text { COVID (N: } 48) \\
\text { Median (IQR)-Mean } \\
( \pm \text { SD) }\end{array}$ & $\mathrm{p}$ \\
\hline Age (years) (N: 114) & $61(13.5)$ & $66.5(20.5)$ & 0,186 \\
\hline \multicolumn{3}{|l|}{ Gender } & 0,235 \\
\hline Female & 20 & 21 & \\
\hline Male & 44 & 29 & \\
\hline BMI $\left(\mathrm{kg} / \mathrm{m}^{2}\right)(\mathrm{N}: 114)$ & $24,7( \pm 4,6)$ & $25,6( \pm 3,7)$ & 0,201 \\
\hline \multicolumn{4}{|l|}{ Surgery type $\left(\mathrm{n}: 177^{*}\right)$} \\
\hline Emergency & 15 & 18 & 0,261 \\
\hline Elective & 81 & 63 & \\
\hline \multicolumn{4}{|l|}{ Neoadjuvant (total N : 144**) } \\
\hline Yes & 17 & 13 & 0,953 \\
\hline No & 64 & 50 & \\
\hline Pre-operative time (days) & $27(22)$ & $25(18)$ & 0,151 \\
\hline \multicolumn{3}{|l|}{ Surgery type } & 0,070 \\
\hline DSG & 35 & 20 & \\
\hline PSG & 0 & 3 & \\
\hline TG & 28 & 25 & \\
\hline Postoperative hospital time (days) & $5(2)$ & $6(3)$ & 0,986 \\
\hline \multicolumn{3}{|l|}{ Complications } & $\mathbf{0 , 0 1 3}$ \\
\hline Yes & 5 & 12 & \\
\hline No & 58 & 36 & \\
\hline \multicolumn{3}{|l|}{ Combined organ resection } & 0,151 \\
\hline Yes & 3 & 6 & \\
\hline No & 60 & 42 & \\
\hline \multicolumn{4}{|l|}{ Tumor markers } \\
\hline $\mathrm{CEA}(\mu \mathrm{g} / \mathrm{L})$ & $1,67(1,87)$ & $2,21(2,39)$ & 0,244 \\
\hline CA $19-9(\mathrm{U} / \mathrm{mL})$ & $15,1(28,9)$ & $10,3(19,9)$ & 0,911 \\
\hline CA $125(\mathrm{U} / \mathrm{mL})$ & $8,3(6,2)$ & $8,7(10,9)$ & 0,163 \\
\hline Pre-operative $\mathrm{Hb}$ (g/dL) & $12,1( \pm 2,0)$ & $12,0( \pm 2,1)$ & 0,902 \\
\hline Post-operative $\mathrm{Hb}$ (g/dL) & $10,3( \pm 1,9)$ & $9,8( \pm 1,8)$ & 0,247 \\
\hline Pre-operative albumin (g/L) & $3,8( \pm 0,3)$ & $3,8( \pm 0,6)$ & 0,668 \\
\hline
\end{tabular}

Significant $\mathrm{p}$ values in bold letters

$S D$ standard deviation, $B M I$ body mass index, $I Q R$ interquartile range

*All patient underwent gastric cancer surgery

** Patients including neoadjuvant chemotherapy
pre-COVID period and 18 in the COVID period $(p=0,261)$. In 13 of 63 patients, NCT were instituted during the pandemic period, while it was 17 of 81 patients in the preCOVID period, there was no statistically significant difference between the groups $(p=0.953)$.

The median waiting time before surgery from endoscopic diagnosis was 27 days (IQR:22) for the pre-COVID period, and it was 25 days (IQR:18) for the COVID group. There was no statistically significant difference $(p=0.151)$. Laboratory tests such as $\mathrm{Hb}, \mathrm{CEA}, \mathrm{CA} 19-9$, CA 125, and albumin were similar between the two groups, and they were shown in Table 1. Relatively same operative procedures were used in different time periods. Median hospital stay was 5 days (IQR:2) before the pandemic, and it was 6 days (IQR:3) during the COVID period $(p=0.986)$. There is no significant difference in the combined organ resections such as colon spleen, liver, and pancreas for pre-COVID and COVID periods $(p=0.151)$. A significant increase was detected in Clavien-Dindo grade 3 or higher complications such as pancreatic fistula, duodenum stump leakage, anastomosis leakage, and bleeding during the COVID period $(p=0.013)$.

Pathological data are shown in Table 2. The clinicopathological characteristics between the two groups for the T stage were similar $(p=0.914)$. The majority of the patients had T3-T4 tumors in both pre-COVID and COVID periods. 
Table 2 Pathological outcomes in both periods

\begin{tabular}{|c|c|c|c|}
\hline Total N: 111 & $\begin{array}{l}\text { Pre-COVID (N: } 63) \\
\text { Median (IQR)-Mean }( \pm \text { SD) }\end{array}$ & $\begin{array}{l}\text { COVID (N: 48) } \\
\text { Median (IQR)-Mean } \\
( \pm \text { SD) }\end{array}$ & $\mathrm{P}$ \\
\hline Pathological report time (days) & $17(12,5)$ & $13(14)$ & 0,063 \\
\hline Stage $\mathrm{T}$ & & & 0,914 \\
\hline $\mathrm{T} 1$ & 8 & 5 & \\
\hline $\mathrm{T} 2$ & 3 & 3 & \\
\hline $\mathrm{T} 3$ & 13 & 12 & \\
\hline $\mathrm{T} 4$ & 39 & 28 & \\
\hline Stage N & & & 0,075 \\
\hline No & 20 & 8 & \\
\hline N1 & 7 & 12 & \\
\hline $\mathrm{N} 2$ & 14 & 7 & \\
\hline $\mathrm{N} 3$ & 22 & 21 & \\
\hline Stage $\mathbf{M}^{*}$ & & & $\mathbf{0 , 0 3 8}$ \\
\hline M0 & 55 & 35 & \\
\hline M1 & 9 & 15 & \\
\hline Pathological stage & & & 0,230 \\
\hline Stage I & 11 & 7 & \\
\hline Stage II & 10 & 6 & \\
\hline Stage III & 34 & 22 & \\
\hline Stage IV & 9 & 15 & \\
\hline Lymphovascular invasion & & & $\mathbf{0 , 0 3 0}$ \\
\hline Yes & 46 & 43 & \\
\hline No & 17 & 5 & \\
\hline Adjacent organ invasion & & & 0,092 \\
\hline Yes & 6 & 10 & \\
\hline No & 57 & 38 & \\
\hline
\end{tabular}

Significant $\mathrm{p}$ values in bold letters

$S D$ standard deviation, IQR interquartile range
Although $\mathrm{N}(+)$ patients were much higher than $\mathrm{N}(0)$ ones in both pre-COVID and COVID periods, fewer N0 patients were diagnosed in the COVID period. $(p=0.075)$. Although there was no statistically significant difference, there was a noticeable increase in the proportion of $\mathrm{N}(+)$ patients $(83 \%$ for COVID, $43 \%$ for pre-COVID period). In contrast to less number of N0 patients in the COVID period, lymphovascular invasion rates were significantly higher $(p=0,030)$. Since cytological evaluation was not routinely done in every patient in whom cytological samples were available, more positive patients were detected in the COVID period. In the pre-COVID period, 6 of 35 patients were found to be cytologically positive, while this figure was 9 of 38 in the COVID period. In addition to these, three patients (one in the pre-COVID period, two in the COVID period) had a macroscopic peritoneal disease and were not undergo gastric resection. As a resume, M1 disease was significantly higher in the COVID group $(p=0,038)$. Otherwise, to increase in stage 4 patients, there was no difference on other stages for pre-COVID and COVID periods $(p=0.230)$.
Adjacent organ invasions and resection rate were increased in the COVID period, but there was no significant difference $(p=0,092)$.

\section{Discussion}

Although it had started longer than 1 year ago, COVID19 pandemic has been continuing to wreck lives throughout the world. The whole world still seeks an answer to whether the COVID-19 pandemic will be over, or people will get used to living with it. Gastric cancer surgeries have been decreased in a given time period from a total number of 81 to 63 at our hospital, the same reduction was detected by several centers [5]. Although the difference was not significant, the emergency gastric cancer surgery rate increased during the pandemia period (increased from 15 to $23 \%$ ). Increase in emergency surgery demand has been explained by the determination of more complicated cancer patients. 
The demographic distributions of operated patients in both periods were similar, but the number of multiorgan resections in the COVID period showed a minimal increase ( $5 \%$ in pre-COVID, $14 \%$ in COVID period), but it did not show a significant difference. Some previous studies have noted that more infective complications could be observed in malignant patients infected with SARS-CoV 2 [6]; the same observation also have been detected in this study and Clavien-Dindo grade 3, and the higher complications were found to be increased in the COVID period $(p=0,013)$. The increased number of surgical complications in the COVID period could be explained by the potential viral contamination of our patients before operation. Nevertheless, it is difficult to withdraw this conclusion from this study since the number of patients is limited.

Several studies revealed that the number of endoscopic procedures has been decreased by $80 \%$ during the pandemia period [7]. This figure is also valid for our country. It is expected that inability to reach the endoscopic evaluation led to difficulty in obtaining correct and early pathological diagnosis. Although there was no significant difference in tumor and node status of gastric cancer patients, important differences were observed in metastatic (M1) patients $(p=0.038)$. Similarly, the prevalence of lymphovascular invasion in pathology specimens of patients in the COVID-period is also statistically higher $(p=0.030)$.

It is not clear the effects of time delay of non-diagnostic period on survival for cancer patients. For endometrial cancer patients, Simon et al. showed that patients who operated in early-stage had worse survival and prognostic results, and they named this as a "waiting time paradox" [8]. Furukawa et al. showed that the patients with gastric cancer whose waiting time is shorter had more advancedstage tumors and worse survival results, respectively [9].

In Brenkmann et al. study, a significant difference was not found in the long-term survival of patients operated at a time less than 5 weeks, and those operated at a time longer than 8 weeks in 2077 gastric cancer patients without neoadjuvant therapy. However, in this study, it was observed that the $\mathrm{T}$ and $\mathrm{N}$ stages of the patients operated at a time less than 5 weeks are significantly more advanced. In both studies, the authors speculated that patients in whom cancers were advanced stages operated earlier, which could affect the results [10]. Yun et al., from Korea, in their high-volume study, showed that increased waiting time had worsened survival in rectum and breast cancer but had no effect on survival in lung, pancreatic, gastric, and colon cancers [11]. In Shin et al. study, 12-week and longer waiting times were related with poor prognosis in breast and colorectal cancers [12].

There were no randomized studies showing the effect of the waiting time on survival in gastric cancer patients. Therefore, it remains uncertain on delays of patients reaching the endoscopy during the period of the COVID19 pandemia and to what extent this delay affects patients' surveillances. Although there is a decrease in the number of patients operated on in our study, more advanced stages of patients were detected during the COVID period.

\section{Conclusion}

The effect of delays on diagnosis on survival for gastric cancer patients has not been determined yet. Pandemia effected survival disadvantage should be further investigated, and inappropriate conditions of oncological patients should be ameliorated by with the changes in health care system.

\section{Declarations}

Ethics Approval This study was approved by the Ethics Committee of the Marmara University (No: 09.2021.356).

Conflict of Interest The authors declare no competing interests.

\section{References}

1. Cinar P, Kubal T, Freifeld A, Mishra A, Shulman L, Bachman J, et al. Safety at the time of the COVID-19 pandemic: how to keep our oncology patients and healthcare workers safe. JNCCN J Natl Compr Cancer Netw. 2020;18:504-9.

2. Torzilli G, Viganò L, Galvanin J, Castoro C, Quagliuolo V, Spinelli A, et al. A snapshot of elective oncological surgery in Italy during COVID-19 emergency: pearls, pitfalls, and perspectives. Ann Surg. 2020;272:e112-7.

3. Rutter MD, Brookes M, Lee TJ, Rogers P, Sharp L. Impact of the COVID-19 pandemic on UK endoscopic activity and cancer detection: a national endoscopy database analysis. Gut. 2021;70:537-43.

4. Bhat PKR, Santosh Kumar K Y, Sorake C, Kulamarva G. Gastrointestinal malignancies and the COVID-19 pandemic: evidencebased triage to surgery. J Gastrointest Surg. 2020;24:2698-9.

5. Li YX, He CZ, Liu YC, Zhao PY, Xu XL, Wang YF, et al. The impact of COVID-19 on gastric cancer surgery: a single-center retrospective study. BMC Surg BMC Surgery. 2020;20:1-7.

6. Pinato DJ, Zambelli A, Bertuzzi A, Marrari A, Saoudi-Gonzalez $\mathrm{N}$, Mirallas O, et al. 3180 Clinical portrait of the SARS-CoV-2 epidemic in European cancer patients. Ann Oncol [Internet]. Elsevier Ltd.; 2020;31:S1366. Available from: https://doi.org/ 10.1016/j.annonc.2020.10.312

7. Parasa S, Reddy N, Faigel DO, Repici A, Emura F, Sharma P. Global impact of the COVID-19 pandemic on endoscopy: an international survey of 252 centers from 55 countries. Gastroenterology [Internet] 2020;159:1579-1581.e5. The American Gastroenterological Association. Available from. https://doi.org/10. 1053/j.gastro.2020.06.009

8. Crawford SC, Davis JA, Siddiqui NA, De Caestecker L, Gillis CR, Hole D. The waiting time paradox: population based retrospective study of treatment delay and survival of women with endometrial cancer in Scotland. Br Med J. 2002;325:196. 
9. Furukawa K, Irino T, Makuuchi R, Koseki Y, Nakamura K, Waki $\mathrm{Y}$, et al. Impact of preoperative wait time on survival in patients with clinical stage II/III gastric cancer. Gastric Cancer [Internet] 2019;22:864-72. Springer Japan. Available from. https:// doi.org/10.1007/s10120-018-00910-y

10. Brenkman HJF, Visser E, van Rossum PSN, Siesling S, van Hillegersberg R, Ruurda JP. Association between waiting time from diagnosis to treatment and survival in patients with curable gastric cancer: a population-based study in the Netherlands. Ann Surg Oncol. 2017;24:1761-9.
11. Yun YH, Kim YA, Min YH, Park S, Won YJ, Kim DY, et al. The influence of hospital volume and surgical treatment delay on longterm survival after cancer surgery. Ann Oncol. 2012;23:2731-7.

12. Shin DW, Cho J, Kim SY, Guallar E, Hwang SS, Cho B, et al. Delay to curative surgery greater than 12 weeks is associated with increased mortality in patients with colorectal and breast cancer but not lung or thyroid cancer. Ann Surg Oncol. 2013;20:2468-76.

Publisher's Note Springer Nature remains neutral with regard to jurisdictional claims in published maps and institutional affiliations. 